\title{
Los mayas y los otros: integración y distinción cultural en el paisaje urbano y rural de Copán
}

The Maya and the others: cultural integration and distinction in the urban and rural setting of Copán

Les Mayas et les autres : intégration et distinction culturelle dans

l'implantation urbaine et rurale de Copan

\section{Felix Kupprat}

\section{(2) OpenEdition}

\section{Journals}

Edición electrónica

URL: https://journals.openedition.org/jsa/16845

DOI: 10.4000/jsa. 16845

ISSN: 1957-7842

\section{Editor}

Société des américanistes

Edición impresa

Fecha de publicación: 15 junio 2019

Paginación: 41-70

ISBN: 978-2-902715-11-4

ISSN: 0037-9174

\section{Referencia electrónica}

Felix Kupprat, «Los mayas y los otros: integración y distinción cultural en el paisaje urbano y rural de Copán», Journal de la Société des américanistes [En línea], 105-1 | 2019, Publicado el 15 junio 2019, consultado el 02 septiembre 2022. URL: http://journals.openedition.org/jsa/16845 ; DOl: https:// doi.org/10.4000/jsa. 16845 


\title{
Los mayas y los otros: integración y distinción cultural en el paisaje urbano y rural de Copán
}

\author{
Felix KuPPRAT *
}

Las relaciones interculturales o interétnicas en los sitios mayas han sido poco estudiadas, a pesar de su relevancia para entender los desarrollos urbanos y sociales en el periodo Clásico. Esto se debe en gran medida a los problemas metodológicos de definir marcadores étnicos y distinguir influencias de identidades culturales. No obstante, hay casos en que podemos rastrear determinadas identidades colectivas distintivas dentro de un sitio e inferir ciertas dinámicas poblacionales y sociales que tienen un impacto político concreto. Este trabajo explora nuevas formas de entender la identidad maya en el Estado regional de Copán a través de un análisis epigráfico comparativo que responde a datos arqueológicos y bioarqueológicos recientes y al patrón de asentamiento. Tratándose de un sitio en la periferia del área maya, se muestra que las élites desarrollaron una identidad cultural que se basa en la alta cultura de Tikal del siglo v d.C., la cual fue instrumentalizada para integrar a una población multi-étnica bajo un modelo ideológico hegemónico. [Palabras claves: Mayas clásicos, Copan, identidad étnica, discurso monumental, distinción cultural.]

The Maya and the others: cultural integration and distinction in the urban and rural setting of Copán. Intercultural and interethnic relations within Maya sites have received little attention, despite their relevance for our understanding of urban and social developments during the Classic period. One reason for this is the methodological problem of defining ethnic markers and distinguishing cultural influences from cultural identities. Nevertheless, in some cases, there is sufficient data to trace distinctive collective identities within a site and to infer certain dynamics of population development that had a concrete political impact. This article explores new ways of approaching Maya identity in the regional state of Copan by the means of a comparative epigraphic analysis that responds to settlement patterns and recent archaeological and bioarchaeological data. At this site on the periphery of the Maya world, the sociopolitical authorities developed a cultural identity based on the elite culture of 5th-century Tikal, which was instrumentalized in order to integrate a multi-ethnic population under a hegemonic ideological model. [Keywords: Classic Maya, Copan, ethnic identity, monumental discourse, cultural distinction.]

* Universidad Nacional Autónoma de México, Programa de Becas Posdoctorales en la UNAM, Becario del Instituto de Investigaciones Antropológicas, México [kupprat@gmail.com]. 
Les Mayas et les autres : intégration et distinction culturelle dans l'implantation urbaine et rurale de Copan. Malgré leur importance pour la compréhension des dynamiques urbaines et sociales durant la période classique, les relations interculturelles et interethniques au sein des sites mayas ont fait l'objet de peu d'attention. Une des raisons à cela réside dans la difficulté méthodologique qu'il y a de définir archéologiquement des marqueurs ethniques et de distinguer les influences de différentes entités culturelles. Dans certains cas toutefois, nous disposons de suffisamment de données pour reconnaître des identités collectives au sein d'un site et, à partir de là, pour cerner certaines dynamiques sociales et démographiques et leur impact politique. Cet article propose une nouvelle approche de l'identité régionale maya du site de Copan à travers une étude épigraphique comparative, croisée avec des résultats archéologiques et bioarchéologiques récemment publiés. Nous suggérons que les élites de ce site en périphérie du monde maya ont développé une identité culturelle inspirée de la culture élitaire $d u v^{e}$ siècle de Tikal. Cette dernière a été instrumentalisée afin d'intégrer une population multi-ethnique, dans le cadre d'un modèle idéologique hégémonique. [Mots-clés : Maya, époque classique, Copan, identité ethnique, discours monumental, distinction culturelle.]

Los estudios sobre el urbanismo en Mesoamérica, es decir, el desarrollo de formas específicas de organización e interacción social en áreas con una alta concentración de estructuras habitacionales, han estado muy ligados a la definición de las jerarquías políticas. En algunos casos, se ha empezado a tomar en cuenta el factor de las distinciones culturales o étnicas en el debate sobre las formas que adquirió la vida urbana en relación a un esquema político concreto. No obstante, la identificación de casas o barrios con identidades étnicas específicas o con poblaciones multiétnicas sólo ha sido posible en casos excepcionales, como en Teotihuacan (Rattray 1987; Price, Manzanilla y Middleton 2000; Manzanilla 2015). Para el área maya, se han planteado hipótesis similares basadas en los patrones de asentamiento y prácticas rituales asociadas (Becker 2009), el análisis de patrones de migración (Price et al. 2008), las prácticas de modificación craneal (Tiesler 2014, p. 224-226) o el uso de lenguas vernáculas específicas (Lacadena García-Gallo y Wichmann 2002). Es de esperar que la diversidad cultural fuera mucho más pronunciada en la periferia de la llamada área maya -en sitios como Comalcalco, Toniná o Copán-que en las tierras bajas mayas centrales o incluso las del norte.

Combinando análisis epigráficos y espaciales, aquí se mostrará, desde una perspectiva diacrónica, cómo identidades culturales y étnicas heterogéneas fueron dialogadas, transformadas y controladas en Copán a lo largo del periodo Clásico (250-900 d.C.), especialmente contrastando y vinculando el centro urbano con las áreas periféricas y el hinterland rural. Un análisis espacial, formal e intertextual de estelas y altares formará la base para reconstruir no sólo la identidad cultural de la élite gobernante, sino también un imaginario 
de lo no maya. Esta dicotomía tiene implicaciones profundas para nuestro entendimiento de las dinámicas poblacionales en Copán.

Desde la década de 1980 se ha postulado la presencia de grupos "mayas" y "lencas" en el área central de Copán (Gerstle 1988). En investigaciones subsecuentes esta dicotomía cultural fue desarrollada en cuestiones de "influencias", tanto en el núcleo urbano (Fash W. 2005, p. 91-93; Maca 2015, p. 184-186) como en el área rural del valle del río Copán y en los valles cercanos (Canuto 2002, 2004; Canuto y Bell 2013). Las diferentes prácticas culturales que pudieron haber servido de marcadores étnicos abarcan la producción cerámica (Viel 1999), la arquitectura (Sharer y Traxler 2006) y la deformación craneal (Suzuki 2015, p. 251-263). Además, estudios bioarqueológicos recientes han confirmado que Copán recibió grandes cantidades de migrantes a lo largo del periodo Clásico, tanto de las tierras bajas mayas, como de las tierras altas de la actual Guatemala y de la región centroamericana al este de Copán (Price et al. 2010, 2014; Miller 2015, p. 207-233; Suzuki 2015, p. 187-220). Ante este panorama no solo debemos cuestionar qué tan representativo es Copán para "la cultura maya", sino también por qué hemos tardado tanto tiempo en abordar este tema. Parto de la hipótesis de que la población clásica de este sitio construyó identidades distintas cuyas expresiones tuvieron implicaciones sociopolíticas. La postulada hegemonía de un grupo maya requería de estrategias específicas para la convivencia e interacción sustentable dentro de la ciudad y del Estado regional.

\section{Copán y los mayas}

La clasificación de Copán como "ciudad maya" se debe, por lo menos inicialmente, a la gran cantidad de monumentos esculpidos y arquitectura monumental que refleja las prácticas comunes en los centros sociopolíticos de las tierras bajas al noroeste de este sitio. No obstante, la presencia de una población que se puede caracterizar como maya en el valle de Copán empezó mucho más tardío que en las capitales culturales de las tierras bajas centrales como Tikal o Calakmul.

Durante el Preclásico y Protoclásico (2000 a.C.-250 d.C.), la cultura material en Copán se vinculaba, en distintas épocas, con la costa del Pacífico, El Salvador y las tierras altas de Guatemala, además de presentar fases de regionalización (Viel 1999; Viel y Hall 2000; Fash W. 2001, p. 64). La aparición de rasgos peteneros arquitectónicos y cerámicos en el valle de Copán (Longyear 1952; Viel y Hall 2000; Sharer et al. 2005) coincide con la tradición literaria de la fundación de la dinastía clásica de Copán a principios del siglo v d.C. ${ }^{1}$ Los textos

1. El texto del Altar Q, dedicado en 776 d.C., fecha la llegada del fundador dinástico para el año 427 d.C., mientras que el texto temprano de la Estela 15 relata la celebración de fines de periodo por parte del mismo individuo para 406 (Stuart 2004, p. 223). 
jeroglíficos atribuyen este suceso a K'ihnich Yax K'uk' Mo '2 (Stuart 2000, p. 490494) quien posteriormente fue venerado en Copán como antepasado deificado, por lo menos hasta principios del siglo IX (Fash B. 1992, p. 99-101; Agurcia Fasquelle y Fash W. 2005, p. 232-237). La huella de ${ }^{87} \mathrm{Sr} r{ }^{86} \mathrm{Sr}$ de su osamenta, hallada en la tumba de la estructura Hunal (Entierro 95-2), en los estratos más tempranos de la Acrópolis de Copán, indica que creció en la región del Petén (Buikstra et al. 2004, p. 210), mientras que el epíteto Uxwitza' ch'aho'm/ajaw en las estelas 63 y J de Copán sugiere vínculos con la élite gobernante de Caracol (Stuart 2007). Esto indica que el Estado clásico de Copán fue establecido en consecuencia de una colonización de un grupo petenero; es a partir de la formación del Estado de Yax K'uk' Mo' y sus sucesores que podemos claramente hablar de Copán como un sitio con rasgos mayas.

El establecimiento de un nuevo Estado bajo el control de un grupo de peteneros en Copán se debe entender en el contexto de la reconfiguración política en las tierras bajas centrales, marcada por la "llegada" del kalo 'mte' Siyaj K'ahk' en Tikal en 378 d.C., la cual fue mencionada en las inscripciones monumentales de una cantidad considerable de sitios en el Petén (Stuart 2000, p. 467-490). Los cambios dinásticos en Tikal, provocados por este evento (para un resumen ver Martin y Grube 2008, p. 29-36), tuvieron un impacto social directo por lo menos hasta 445 d.C. cuando se dedicó la Estela 31 en Tikal, la cual contiene la narrativa más tardía y más detallada de dicho episodio. El Estado copaneco clásico nace de este ambiente de transición política. Es la época en que los gobernantes empiezan a utilizar el título supremo de $k^{\prime} u h u l$ ajaw, 'señor divino', y en la cual el discurso monumental enfatiza lazos estrechos entre los gobernantes de Tikal y el centro de México.

Copán parece haberse fundado junto con Quiriguá, alrededor de $50 \mathrm{~km}$ al norte de la primera (Sharer 1978, p. 63; 1988, p. 59-61), donde a partir del siglo v se cuenta con evidencias claras de arquitectura monumental y conexiones cerámicas con el Petén (Ashmore 1984, p. 372-377). Las estelas inscritas más tempranas de este sitio son de finales del siglo v (Sharer 1990, p. 103, tab. 1) y textos posteriores postulan que los gobernantes de Quiriguá fueron subordinados a los de Copán, por lo menos hasta la decapitación de Waxaklajuun Ubaah K’awiil de Copán en 738 d.C. (Looper 1999, p. 264-271).

Contamos con muy pocos datos epigráficos sobre la interacción política de los gobernantes de Copán con otras élites del área maya. Desde la década de 1990 se ha especulado sobre una conexión entre Tikal y Copán (Fahsen, Schele y Grube 1995; Grube, Schele y Fahsen 1995; Schele, Grube y Fahsen 1995). Una posible mención de Siyaj K'ahk' en la Piedra Xukpi de Copán, así como la referencia a un individuo con el nombre $K^{\prime} u\left[k^{\prime}\right] M^{\prime}$ ' en el Hombre de Tikal

2. Cursivas marcan transcripciones (incluyendo nombres de humanos, lugares, dioses, etc.), negritas transliteraciones. 
siguen siendo los indicadores contemporáneos más explícitos de esta relación (Figura 1). Desafortunadamente, ambos nombres aparecen en contextos sumamente problemáticos -el primero por su extraña posición sintáctica al final del texto y el segundo por el estado fragmentado del soporte-, así que no es posible averiguar si realmente se trata de los mismos individuos conocidos de la historia de Tikal y Copán, respectivamente. Además, se ha sugerido que los gobernantes de Copán mantuvieron relaciones políticas directas con Caracol (Grube 1990) y Río Azul (Grube, Schele y Fahsen 1995) en el Clásico temprano (250-600 d.C.), así como con El Palmar, Campeche (Tsukamoto et al. 2015, p. 211-214), y Palenque (Schele y Grube 1987) en el Clásico tardío (600-800 d.C.). No obstante, la mayoría de estas propuestas siguen siendo problemáticas $^{3}$; únicamente las referencias a Waxaklajuun Ubaah K'awiil de Copán en la Escalinata Jeroglífica de El Palmar constituyen un indicador concreto para postular la interacción directa entre actores políticos de ambos sitios. Las relaciones que mantuvo Quiriguá con los sitios mayas al norte son aún menos claras, ya que la única referencia documentada de un individuo maya foráneo en este sitio es la de Wamaaw K'awiil en la Estela I, quien es caracterizado como señor de Chi'knaahb, lo cual coincide con uno de los topónimos principales de Calakmul. La acción que Wamaaw K'awiil realiza en el texto no es clara; no obstante, se ha sugerido que estuvo involucrado en el conflicto con Copán en 738 d.C. (Looper 1999, p. 268-271), el cual tuvo lugar pocos años después de que residentes de El Palmar expresaran sus lazos con Waxaklajuun Ubaah K'awiil de Copán y el gobernante de los Kanu'l en Calakmul (Tsukamoto et al. 2015, p. 211-217).

A pesar de la escasez de referencias claras a agentes foráneos en Copán y Quiriguá, los textos escritos ofrecen otra posibilidad de acercarnos a las relaciones que tuvieron sus élites con las que habitaban al norte y al oeste. La identificación y comparación de motivos literarios ha reafirmado la hipótesis

3. En la Estela 16 de Caracol (534 d.C.), se encuentra el glifo emblema de la dinastía de Copán, precedido por un posible nombre personal que por su composición jeroglífica y el marco cronológico del texto no permite una correlación clara con uno de los dinastas conocidos. El nombre de un personaje de Río Azul en la Estela 20 de Copán también es problemático, por la falta de contexto y la presencia de glifos no descifrados en la frase antroponímica en cuestión. La evidencia de una relación entre las élites de Copán y Palenque consiste en una expresión de parentesco que consta que el decimosexto gobernante Yax Pahsaj Chan Yopaat fue hijo de Ixchak [...] Xook, la cual lleva el glifo emblema de Matwiil. Este glifo emblema aparece únicamente en Palenque y fue portado por varios gobernantes, además del glifo emblema dinástico de Baake'l. Sin embargo, el glifo emblema de Matwiil hace referencia a un lugar mitológico y parece haber sido adquirido por algunos gobernantes palencanos a través de cierto desempeño ritual (Helmke 2012, p. 95-100). Tomar el glifo emblema de Ixchak [...] Xook como indicador de su procedencia es solo una de las posibilidades para interpretar este título. No obstante, el uso del glifo emblema de Matwiil claramente indica lazos intelectuales entre los dos sitios. 


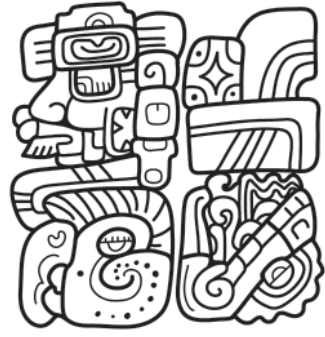

a

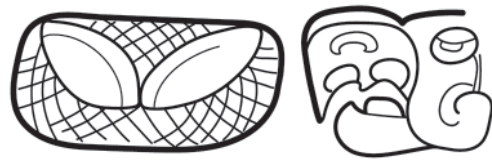

b

Fig. 1 - a) El nombre de K'ihnich Yax K'uk'Mo'seguido por el título ajaw (o [y]ajaw) y el nombre de Siyaj K'ahk'; b) el nombre K'u[k'] $M o$ ' en el texto del Hombre de Tikal (E2-F2). Dibujos del autor;

1a) basado en el dibujo de D. Stuart (2004, p. 244, fig. 11.18).

de una colonización de Copán y Quiriguá desde Tikal o sus alrededores cercanos. Además, hay que replantear que esta conexión involucraba a una serie de sitios en Belice (Caracol, Pusilha, Nim Li Punit, entre otros). Las imágenes y los textos clásicos no sólo son fuentes históricas explícitas, es decir, no son simples manifestaciones de relatos sobre el pasado, sino también son artefactos y deben tratarse como tales a nivel arqueológico. Me refiero tanto a la materialidad de los textos, como a sus contenidos simbólicos, los cuales expresan y reflejan rasgos culturales. Estos rasgos culturales, los componentes de los textos, obedecen a las mismas dinámicas de tradición e innovación que otros, como la cerámica, la lítica o la arquitectura; sus estilos, técnicas y funcionalidad reflejan procesos sociales y su análisis comparativo revela patrones de transmisión. Por ende, el trabajo epigráfico ya no se puede restringir a la extracción de los mensajes inmediatos, como son las secuencias dinásticas, eventos sociopolíticos y relaciones de parentesco, los cuales, además, suelen reflejar narrativas de relevancia local; tenemos que poner el mismo énfasis en las formas de composición, es decir, en los estilos narrativos, las fórmulas canónicas y las tradiciones literarias, las cuales tienen el gran potencial de revelar la interacción de autores más allá del entorno inmediato de los gobernantes.

La influencia intelectual de Tikal en Copán se refleja sobre todo en el uso de ciertas fórmulas rituales, de teónimos $\mathrm{y}$, hasta cierto grado, de narrativas mitológicas. Vemos, por ejemplo, que el nombre de una serpiente acuática, [...] Ha' Ek' Juun Witz', que por primera vez aparece en los textos tempranos de Tikal (estelas 31 y 3; Figura 2), fue retomado por escribas copanecos en el siglo VII y a principios del siglo viII, mientras que cayó en desuso en el resto del área maya. En las tierras bajas centrales, el teónimo fue sustituido por el de Yax Chit Juun Witz' Naah Kan, atestiguado desde 672 d.C. en Calakmul (Estela 9) 


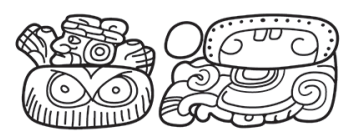

a
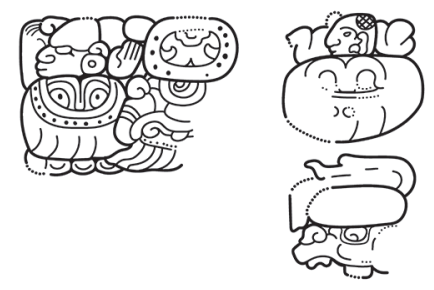

d

e

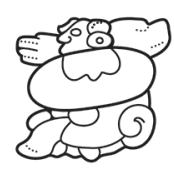

b

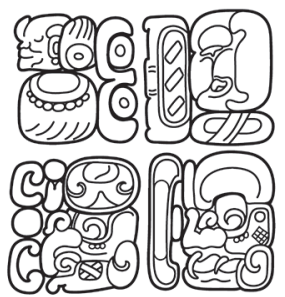

$f$

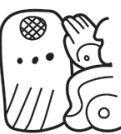

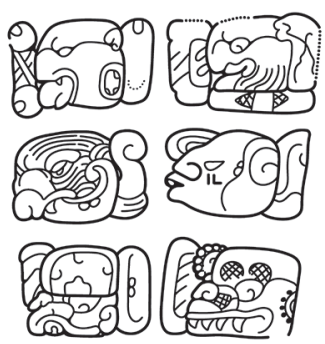

h

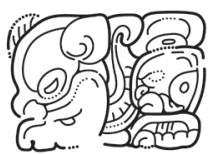

I

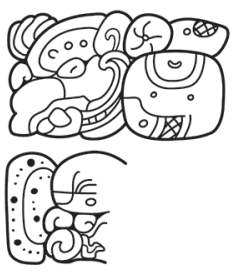

m

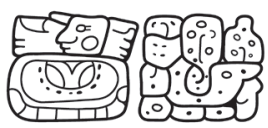

C

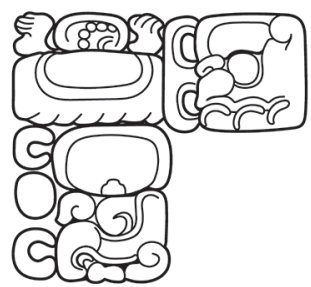

g

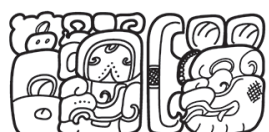

j

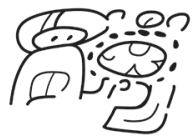

k

Fig. 2 - Desarrollo de los teónimos [...] Ha' Ek'Juun Witz', Yax Chit Juun Witz'Naah Kan y Yax Chit [...] Kan (selección). [...] Ha' Ek' Juun Witz' (Clásico temprano): a) Tikal, Estela 31 (445 d.C.); b) Tikal, Estela 3 (488 d.C.). Nombre derivado: c) Uaxactun, cajete (Tzakol 3). [...] Ha’ Ek’ Juun Witz' (Clásico tardío): d) Copán, Estela P (623 d.C.); e) Copán, Estela J (702 d.C.). Teónimos combinados: f) Quiriguá, Estela J (756 d.C.); g) Quiriguá, Estela D (766 d.C.); h) Copán, Altar J' (siglo viII d.C.). Yax Chit Juun Witz’ Naah Kan: i) Copán, marco de base de la Estela N (761 d.C.); j) Pomoná, Tablero 1 (771 d.C.); k) Calakmul, Estructura II, Tumba 4, máscara funeraria (siglo viI). Yax Chit [...] Kan y teónimos derivados: 1) Copán, Estela P (623 d.C.); m) Copán, Estela 6 (682 d.C.); n) Palenque, Tablero del Palacio (720 d.C.). Dibujos del autor según dibujos de W. Coe (a, b; Jones y Satterthwaite 1982, fig. 52, 4), V. Lucas y R. Gonzales (c; Smith R. 1955, fig. 8g, 81s), B. Fash (d, h, 1, m; Schele 1990a, fig. 10, 1990b, p. 2, fig. 1; Fash y Fash 2006, p. 121, fig. 4), L. Schele (e, i, j, n; Schele y Schele 2000, no. 1015, 1018, 7628, 121), A. Hunter (f, g; Maudslay 1902, t. 2, ilustración 46, 26) y S. Martin (k; Martin 2000, p. 43). 


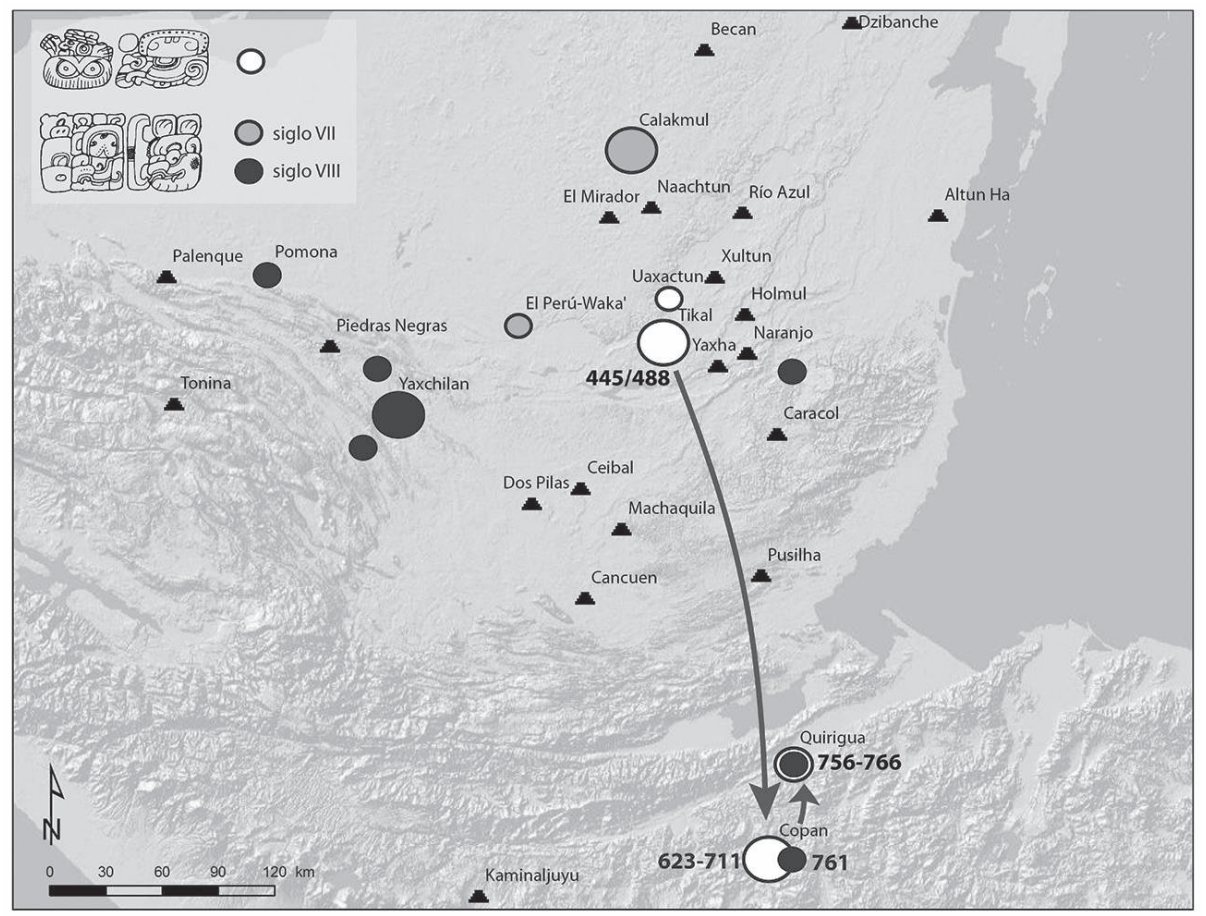

Fig. 3 - Mapa que muestra la distribución espacial y temporal de los teónimos [...] Ha'Ek'Juun Witz'(blanco) y Yax Chit Juun Witz'Naah Kan (gris/negro). Elaborado por el autor.

y posteriormente sobre todo en Yaxchilán y sus alrededores (Figura 3) ${ }^{4}$. Lo que nos importa en esta ocasión es que los escribas de Copán siguieron utilizando el teónimo arcaico, ignorando las innovaciones peteneras durante varias décadas. En 756 y 766 se observa una fusión de [...] Ha' Ek' Juun Witz' y Yax Chit Juun Witz' Naah Kan en las estelas J y D de Quiriguá, respectivamente; un fenómeno que también ocurre en el Altar J' de Copán que probablemente fue elaborado en el siglo VIII. Únicamente en el marco de base de la Estela $\mathrm{N}$ en Copán (761 d.C.) el teónimo fue escrito sin los elementos arcaicos.

Un patrón parecido se observa con respecto al nombre del dios "GI". En el Clásico temprano, esta deidad fue representada en una gran variedad de objetos procedentes de las tierras bajas centrales, sobre todo de Tikal (Hellmuth 1987,

4. Un culto a esta deidad parece haber sido consolidado por la dinastía Kanu'l en Calakmul y posteriormente adaptado por las élites de Yaxchilán y otros sitios de la región del Usumacinta. Además, el teónimo aparece de manera aislada en Ek Balam y en el "Vaso de Cuychen" (Helmke et al. 2015, p. 22-24). 
p. 79-100). Su nombre 5 se identifica claramente en el Marcador de Tikal (416 d.C.), así como en las estelas 31 (445 d.C.), 2 (475 d.C.), 6 (514 d.C.) y tal vez 17 (siglo vi) del mismo sitio. De nuevo, observamos que el mismo teónimo reaparece en Copán en las estelas I (668 d.C.) y J (702 d.C.), mientras que cae en desuso en las tierras bajas centrales ${ }^{6}$.

En ambos casos, la tendencia es la misma: los escribas copanecos adaptan motivos literarios del Clásico temprano tikaleño. Estos motivos no tienen continuidad en Tikal, donde un hiato de inscripciones monumentales marca no sólo la transición del Clásico temprano al tardío, sino también un cambio profundo en la tradición literaria. No obstante, en Copán, las referencias al canon temprano petenero se encuentran hasta finales del Clásico tardío y tienen repercusiones en las inscripciones de su vecino Quiriguá. Lo mismo sucede con los dioses remeros, cuyo culto en Copán parece tener sus raíces en Tikal (Velásquez García 2010; Sánchez Gamboa 2012). Aparte de las referencias a deidades particulares, también existen paralelos narrativos más extensos entre los textos tikaleños y los copanecos. Un pasaje en el texto de la Estela 31 de Tikal cuenta de un evento (posiblemente un fin de periodo) celebrado por "Jaguar Foliado" en Chihka' (perteneciente a o cercano de un lugar no descifrado). Al parecer, las referencias a fines de periodo celebrados por "Ajaw Foliado" que se encuentran en Pusilha (Estela P de 647 d.C. y Estela K de 672 d.C.) y Copán (Estela I de 676 d.C. y Estela 4 de 737 d.C.) son una adaptación del mismo mito. Esto no solo indica relaciones culturales entre Pusilha y Copán, sino también que en ambos sitios hubo una orientación hacia la literatura tikaleña antigua durante el Clásico tardío ${ }^{7}$.

Mientras que la relación cultural entre Copán/Quiriguá y los sitios al sur de Belice (particularmente Pusilha y Nim Li Punit) parece haber sido de más larga duración (Stuart y Grube 2000, p. 5-6; Prager, Volta y Braswell 2014,

5. La lectura es aún problemática. La secuencia común es T4.533.217c.1011.173 (NAH?SAK-?YUK-GI-mi), mi siendo un posible complemento fonético del signo T1011.

6. En esta época empieza la adoptación de esta deidad por parte de la corte de Palenque. Algunos incensarios del Clásico temprano, así como el Tablero Oval del Palacio (mediados del siglo VII), aún reflejan la forma y el nombre canónico petenero, pero pocos años después se nota la transformación al GI de la triada de dioses patronos locales que se menciona por primera vez en la escalinata jeroglífica de la Casa C (alrededor de 661 d.C.). Además, hay que mencionar que GI no desaparece completamente de las tierras bajas centrales. Es representado, por ejemplo, como uno de los dioses en el "Vaso de los Siete Dioses" (Stuart 2017, p. 261) y su máscara es llevada por un gobernante en la Estela 2 de Ceibal (Hellmuth 1987, p. 85).

7. Es probable que en las estelas 15 y 18 de Copán se hayan incorporado los nombres de los númenes ancestrales tikaleños Sak Hix Muut y Yax Ehb Xook (Martin y Grube 2008, p. 195) en las frases nominales de los primeros dos gobernantes copanecos, respectivamente. No obstante, el mal estado de conservación de ambos monumentos no permite confirmar esta hipótesis. 
p. 283-285, 299; Somerville, Schoeninger y Braswell 2016, p. 154, 156-157), el vínculo con Tikal parece remontarse al Clásico temprano, especialmente al siglo v. Desde la época de la fundación hasta mediados del Clásico tardío, el canon literario tikaleño temprano servía como inspiración constante para la elaboración de nuevos textos, en una tradición escultórica y literaria cuyo desarrolló muestra un alto grado de autonomía local (ver Kupprat 2015, p. 207-226; Bíró 2017, p. 1-26). Esto nos indica que las élites mayas copanecas, a pesar de interactuar solo periféricamente con las tierras bajas centrales en los siglos vI a VII, básicamente mantuvieron una identidad cultural como herederos de la gloria tikaleña de la época de la post-entrada. Esta identidad fue, necesariamente, actualizada, ampliada y modificada de acuerdo con las reconfiguraciones que sufría la ciudad a lo largo de los siglos, pero por lo menos hasta mediados del siglo VIII los recuerdos colectivos de Tikal del siglo v son más pronunciados que en cualquier otro sitio del área maya, e incluso en Tikal mismo. La versión copaneca de la identidad petenera se construía frente a la interacción cotidiana de las élites mayas con otros grupos.

\section{Espacio, ritual y desarrollo poblacional}

En general, las ciudades mayas se caracterizan por presentar patrones de asentamiento dispersos con conjuntos habitacionales alejados entre sí. Es esta propiedad que ha provocado dudas con respecto a la viabilidad de aplicar el concepto de "ciudad" a los asentamientos clásicos (Webster y Sanders 2001, p. 59-64). No obstante, la presencia de centros cívico-ceremoniales como lugares centrales y de infraestructura de tránsito y abastecimiento (p. ej., aguadas) justifican por lo menos la noción general de "núcleos urbanos" (ver Sanders y Webster 1988, p. 529-535; Chase, Chase y Haviland 1990), mientras que la ciudad debe entenderse como estructura espacial amplia que abarca distritos y barrios (Smith M. 2010, p. 148; Smith M. 2011; Arnauld 2012; Isendahl y Smith 2013; Smith M. y Novic 2012, p. 11-12).

La población del núcleo urbano de Copán interactuaba con la de su hinterland, una serie de zonas residenciales, o "comunidades" distribuidas a lo largo del valle del río homónimo (Figura 4). Por esto, Copán ha sido tratado en muchas ocasiones desde la perspectiva de un "Estado regional" en lugar de una "ciudad". Este Estado abarcaba e involucraba a comunidades a distancias considerables, incluyendo centros secundarios como Río Amarillo (Fash W. 1983; Fash y Long 1983; Webster, Freter y Gonlin 2000, p. 74-76; Canuto 2002, 2004; Canuto y Fash 2004, p. 59-60). El área nuclear era una zona muy restringida, abarcando el Grupo Principal, Las Sepulturas al este y El Bosque al oeste (ver Webster, Freter y Gonlin 2000, p. 8, fig. 1-4), y probablemente el área del poblado moderno Copán Ruinas. Durante el Clásico temprano, el centro cívico-ceremonial del Estado copaneco parece haberse encontrado en esta 


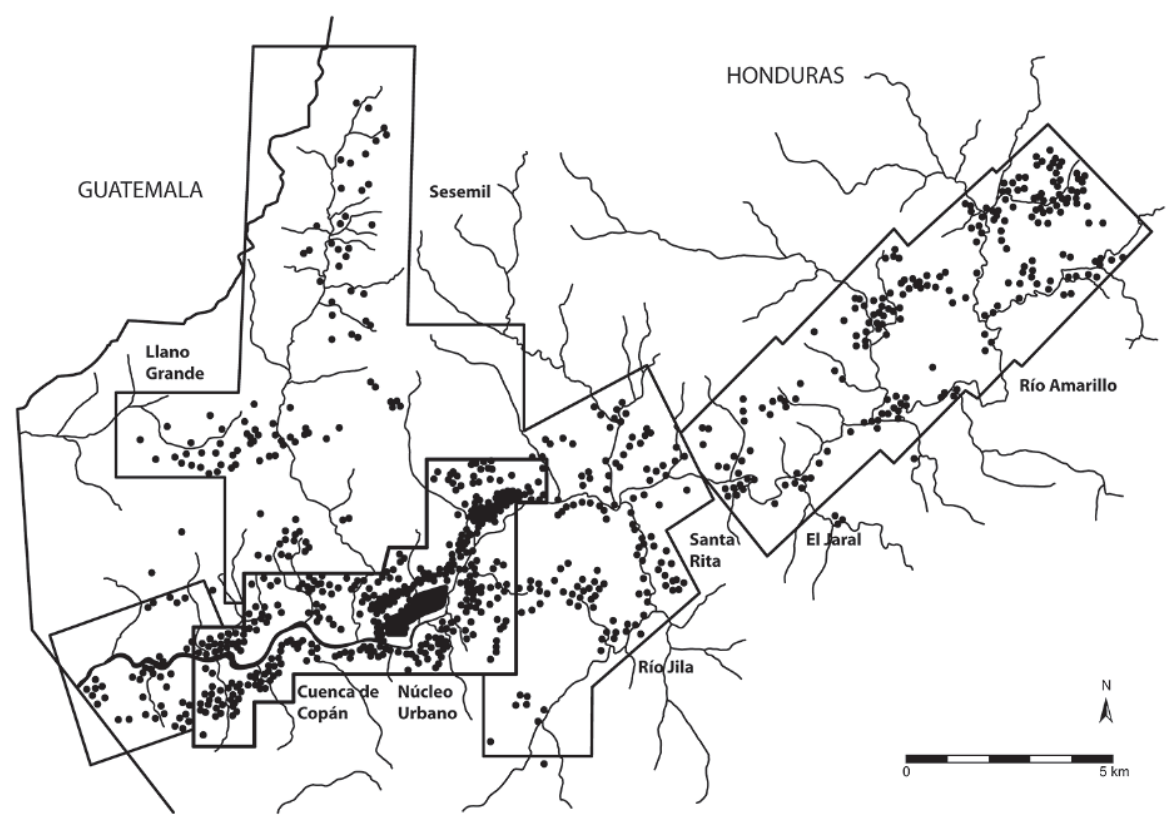

Fig. 4 - Mapa del valle de Copán indicando la ubicación de sitios registrados (redibujado de Webster, Freter y Gonlin 2000, p. 33, fig. 3-1).

última, a aproximadamente $1.5 \mathrm{~km}$ al oeste del Grupo Principal (Fash W. 2001, p. 87-89). Morley (1920, p. 124, fig. 22) denominó este centro "Grupo 9" e identificó por lo menos 18 monumentos esculpidos en esta área. La estela más tardía y, además, la única completa de este grupo es la Estela 7 (613 d.C.), la cual fue erigida sobre un basamento elevado al suroeste de la plaza moderna. Algunos monumentos esculpidos más tardíos, como los altares S (731 d.C.), T (783 d.C.) y U (795 d.C.), también fueron encontrados en el Grupo 9 e indican un uso ritual de este espacio hasta finales del siglo viII. El abandono del Grupo 9 como centro ceremonial principal posiblemente se relaciona con un evento de destrucción que resultó en la fragmentación de virtualmente todos los monumentos esculpidos públicos anteriores a 564 (Sharer 2004, p. 305-310). Después de esto, el centro urbano fue trasladado al Grupo Principal (Figura 5) que había crecido constantemente, convirtiéndose poco a poco de un complejo residencial-palaciego de $\operatorname{Yax} K^{\prime} u k^{\prime}$ Mo' en el foco para la veneración ancestral del fundador dinástico y sus sucesores (Sharer et al. 2005, p. 151-191). La Estructura Rosalila, la versión contemporánea del santuario para Yax K'uk' Mo' como dios solar, (Taube 2004, p. 280-283; Agurcia Fasquelle y Fash 2005) marcaba el centro de la Acrópolis como espacio semi-privado para la realización de ritos dinásticos y políticos ante y junto con un público de tamaño controlado, 


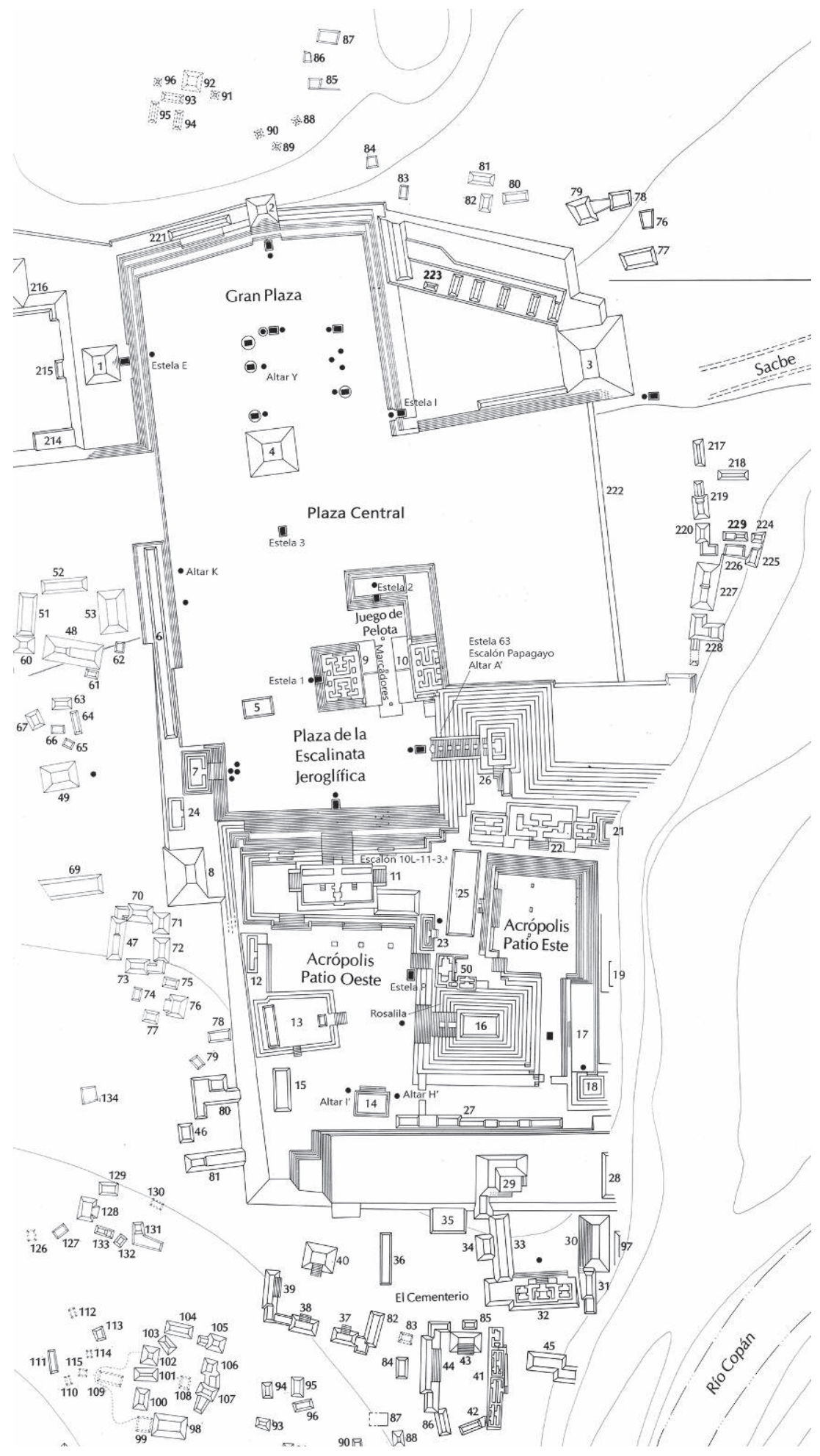

Fig. 5 - Mapa del Grupo Principal indicando la ubicación de los monumentos escultóricos dedicados antes de 700 d.C. (modificado de Fash y Long 1983, mapa 12). 
mientras que la Gran Plaza y la cancha de juego de pelota inmediatamente al norte de la Acrópolis formaron el nuevo centro ceremonial público ${ }^{8}$.

El siguiente siglo (VII) es caracterizado por un notable crecimiento poblacional en todo el valle de Copán (Webster 2005, p. 42-43). El decimosegundo gobernante, K'ahk' Uti' Juun Witz' K'awiil, reconfiguró el grupo 10L-2 al sur de la Acrópolis como palacio dinástico (Andrews y Bill 2005, p. 241-242, 244-247). También en la zona habitacional conocida como Las Sepulturas, al este del Grupo Principal, se ha registrado un aumento en la construcción de mampostería en esta época (Webster, Freter y Gonlin 2000). Además, se nota un cambio en los patrones de migración, reflejado en el aumento de inmigrantes del este de la actual Honduras en el Clásico tardío (Suzuki 2015, p. 199-203). La diversificación cultural de la población parece haberse percibido como una amenaza potencial para la integridad de la ideología estatal y el sistema político que sustentaba. Especialmente para el gobierno de K'ahk' Uti' Juun Witz' $K$ 'awiil contamos con una serie de datos que reflejan las estrategias estatales de integración y distinción encaminadas a fortalecer la hegemonía maya tanto en el centro como en la periferia de Copán.

\section{Integración}

En el siglo vII, K'ahk' Uti' Juun Witz' K'awiil siguió con la construcción del Grupo Principal, estableciéndolo definitivamente como centro de la vida ritual, política y, probablemente, económica. Empezó a erigir estelas en lugares estratégicos en la Gran Plaza (estelas E e I) y en la Plaza Central (estelas 1, 2 y 3, Altar K), la cual constituye el nodo de transición principal entre Las Sepulturas y El Bosque. La Estela 3, siendo el monumento más expuesto, fue la primera en portar la imagen del gobernante en dos costados, maximizando la presencia del dinasta en el espacio público. Este principio fue repetido en la Estela 5 (672 d.C.), erigida en el camino hipotético entre el Grupo Principal y el Grupo 9, es decir de nuevo en un camino muy transitado. Este programa de escultura monumental en el centro urbano parece haberse dirigido a los habitantes de la zona nuclear. El gobernante tuvo que estar omnipresente; una necesidad que empezó a plasmarse en la segunda mitad del siglo vi, pues antes

8. El área de la Gran Plaza cuenta con evidencias de ocupación más temprana, desde el Preclásico tardío, mientras que la primera etapa constructiva de la cancha de juego de pelota se remonta por lo menos a la primera mitad del siglo v (Cheek 1983, p. 334-335). No obstante, la definición de los límites de la plaza como aún se observan hoy en día corresponde al inicio de la fase cerámica Coner (ibid., p. 339), es decir a mediados del siglo vII (Andrews and Bill 2005, p. 245, tab. 7.1). 


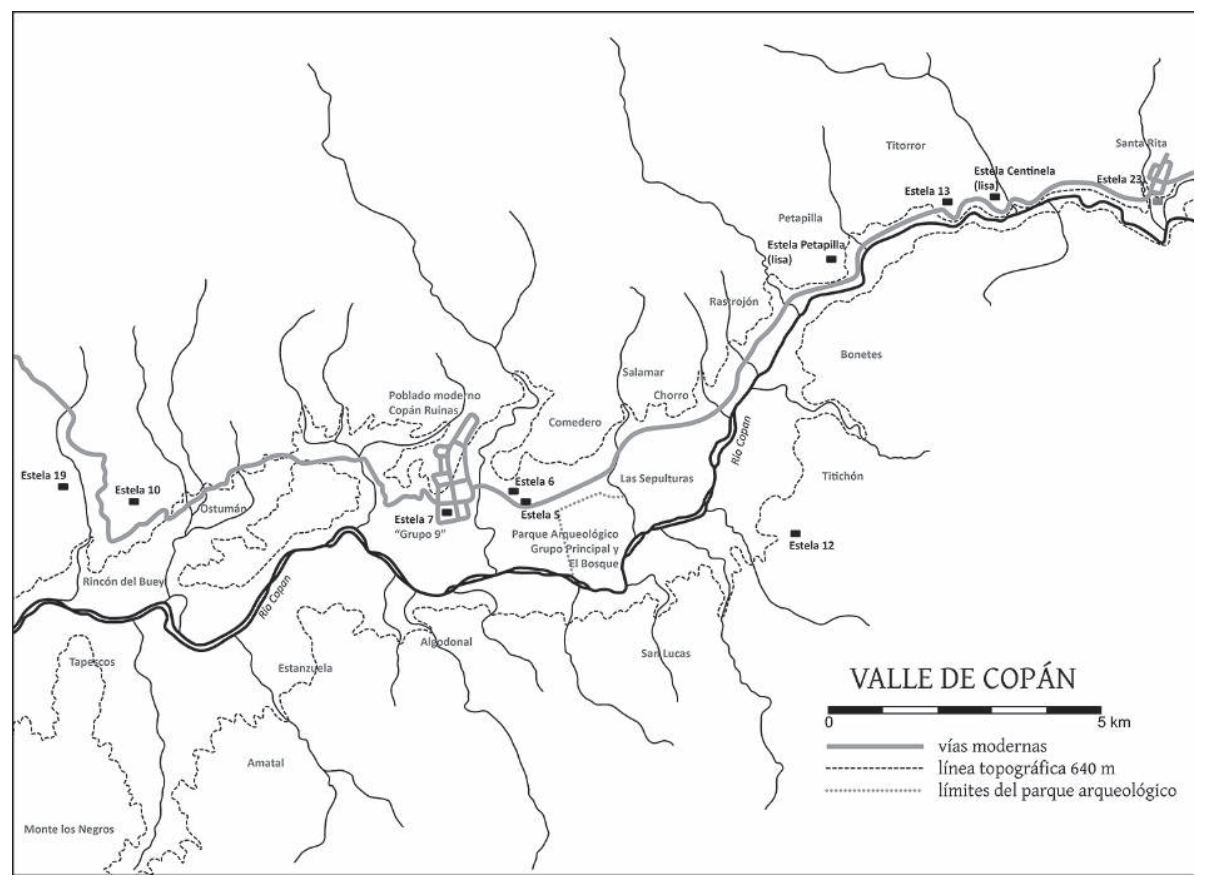

Fig. 6 - Mapa del valle de Copán con las ubicaciones de las estelas del siglo VII (redibujado de Willey et al. 1994, p. 6, fig. 2).

las estelas copanecas eran completamente jeroglíficas, sin retratos o imágenes (Fash B. 2004, p. 259; Kupprat 2015, p. 219)'.

Al mismo tiempo, K'ahk' Uti' Juun Witz' $K^{\prime}$ awiil expandió la esfera ritual más allá del núcleo urbano. En 652 d.C., por lo menos cinco estelas con sus respectivos altares fueron colocados en puntos estratégicos a lo largo del valle (Figura 6), estableciendo áreas rituales con y para la población del hinterland. Es probable que también las estelas lisas "Petapilla" y "Centinela" y los altares asociados correspondan a este programa (Kupprat 2015, p. 206-207). Mientras que algunos de estos monumentos fueron colocados de acuerdo con la observación de fenómenos astronómicos (estelas 10 y 12; Morley 1920, p. 132-134; Carter 2014, p. 35-36), sin asociarse con espacios habitacionales, otros fueron erigidos en plazuelas rodeadas por conjuntos residenciales amplios. Esto último

9. Una excepción es la Estela 35, posiblemente el monumento más temprano de Copán, cuyo fragmento porta la imagen de un personaje antropomorfo, pero carece de glifos (Riese y Baudez 1983, p. 186-190). La propuesta de fechar la Estela 53, la cual tiene texto e imagen, para mediados del siglo v (Bíró 2017, p. 10) es problemática, ya que la referencia a un fin de periodo es paleográficamente poco clara y, además, puede ser parte de una narrativa retrospectiva. 


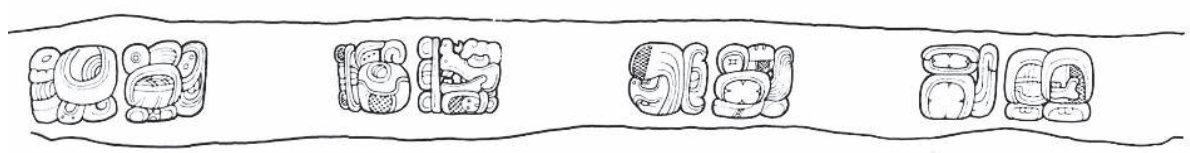

Fig. 7 - Texto en la circunferencia del Altar de la Estela 13 de Copán.

Dibujo de L. Schele (Schele y Schele 2000, no. 1040).

es el caso para las estelas 19 y 23 ubicadas en Hacienda Grande ("Grupo 13"; Morley 1920, p. 14, 143-144) y Santa Rita, respectivamente. La información arqueológica sobre los dos grupos es muy escasa (Maudslay 1902, t. 1, p. 16; Morley 1920, p. 13, 43-144, 146-147; Fash W. 1983, p. 419-423), pero la presencia de estelas en las plazas de ambos grupos indica su importancia dentro del tejido sociopolítico regional del siglo vII.

Las estelas remotas del valle de Copán ciertamente no sólo marcaban un territorio político (Schele y Grube 1988; Fash W. 2001,p. 101-104); las dimensiones políticas de sus funciones se plasman de manera implícita en los contenidos de sus textos. En general, las estelas y los altares de Copán carecen de narrativas autobiográficas detalladas y bélicas, así como de expresiones de parentesco, las cuales son tan importantes en los discursos monumentales de otras partes del área maya. En lugar de estos elementos, los textos enfatizan acciones rituales, incluyendo las dedicaciones de los monumentos mismos, la evocación de dioses y antepasados, la terminación de ciclos calendáricos, actos de ofrenda, etc. (ver Stuart 1992, p. 170). Esto no significa que los textos sean apolíticos; los actores principales de los textos suelen ser los gobernantes quienes, además, enfatizan constantemente su estatus como sucesor legítimo del fundador dinástico. Sin embargo, en Copán se ve claramente que los juegos estela-altar(es) no eran simplemente soportes para mensajes de propaganda política que legitimaban al gobernante; también, y tal vez en primer plano, eran objetos rituales que facilitaban y fijaban una conexión con los dioses en el espacio físico. Las estelas fueron habitadas o poseídas por númenes específicos; tenían nombres 'divinos' ( $k^{\prime} u h k^{\prime} a b a^{\prime}$ ) y marcaban sus alrededores como espacios sagrados. Los nombres de las estelas frecuentemente incorporan el sufijo toponímico -nal y en un caso, el de la Estela 13, el texto del altar correspondiente refiere el lugar donde se ubica como 'chan ch' $e$ ' $n$ del este' (Figura 7) ${ }^{10}$. En estos espacios, los altares servían para presentar y quemar ofrendas, a veces percibidas como alimento para los dioses como indica de nuevo el Altar de la Estela 13. Esta interpretación

10. El término chan ch 'e' $n$, literalmente 'cielo-cueva' o 'cueva del cielo' ha sido interpretado de diferentes maneras -como 'mundo' o 'ciudad' (ver Martin 2004, p. 108; Stuart y Houston 1994, p. 12-13; Hull 2012, p. 105-109)- pero una revisión reciente y extensa ha mostrado que esta expresión probablemente denomine de manera menos específica "aquella parte del mundo donde los dioses actúan y residen" (Tokovinine 2008, p. 156). 
de las estelas, los altares y sus alrededores como lugares sagrados es reforzado por las ofrendas halladas debajo de los monumentos. Muchas estelas en Copán cuentan con cámaras cruciformes subterráneas que no solo protegían ofrendas materiales enterradas, sino también facilitaron reentradas subsecuentes (Strömsvik 1941).

Entonces, la erección de estelas en diferentes localidades claves alrededor del núcleo urbano de Copán fue un acto de establecer o fortalecer santuarios en la zona rural. De esta manera, K'ahk' Uti' Juun Witz' K'awiil extendió la esfera del ritual político más allá del núcleo urbano, integrando la población de diferentes partes del valle en los ritos realizados alrededor de las estelas. En el caso de Copán, el ritual no sólo servía para reforzar una identidad colectiva entre los participantes; el fin era el de establecer esta identidad como base de una comunidad imaginada compuesta de locales y migrantes de diferentes orígenes y costumbres. En este sentido, el ritual fue el principal aglutinador para integrar la población multi-étnica copaneca, tanto en la ciudad, como en sus alrededores.

Este proceso también se ve reflejado en un incremento paulatino de dioses patronos en Copán (ver Baron 2013, p. 180, 219-220, 2016, p. 53; Prager 2013, p. 373-374). Esto significa que nuevos dioses fueron incorporados en el panteón estatal, una dinámica que seguramente no se debe a la invención espontánea, sino más bien a la incorporación de dioses (y sus cultos) que llegaron junto con nuevos pobladores de orígenes foráneos. Justamente en el siglo VII vemos que algunas de las listas de dioses, sobre todo las de las estelas P (623 d.C.) y 13 (652 d.C.) incorporan teónimos que fueron escritos con largas secuencias de fonogramas que resisten interpretaciones etimológicas contundentes. Esto puede indicar un origen no maya de estos nombres y, por ende, de las deidades que son denominadas con ellos. La repetición de los aparentes sufijos -paan y - $t z$ 'in han provocado discusiones sobre posibles etimologías en náhuatl (Bíró y Davletshin 2011; Bíró 2017; Prager y Wagner 2017, p. 11-13). Algunos de estos teónimos aparecen una sola vez en el corpus de inscripciones, pero otros parecen haber tenido una tradición más larga. Dos de los teónimos en la Estela 13, wa-la-cha-li y we-ku-?ma, se representan también en la banqueta esculpida del Templo 11 (Figura 8). En esta última, se aprecia a una serie de antepasados y deidades patronas sentadas sobre tronos en forma de sus nombres jeroglíficos. Mientras que la imagen de we-ku-?ma no incluye elementos que lo distingan de las demás figuras, wa-la-cha-li es representado con elementos diagnósticos que incluyen una diadema y una orejera de concha, ambas atributos del dios maya de la lluvia y del agua Chaahk (García Barrios 2008, p. 81-85), así que wa-la-cha-li parece haber compartido ciertos rasgos con este numen. Por esta correspondencia, se puede emplear la hipótesis de que el nombre -transcrito de manera preliminar como walchaal o walachaal-incorpora la raíz lenca wal, 
Copán, Templo 11, banqueta

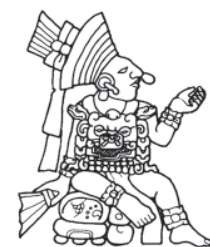

Copán, Estela 13

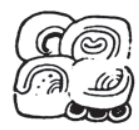

we-ku-?ma
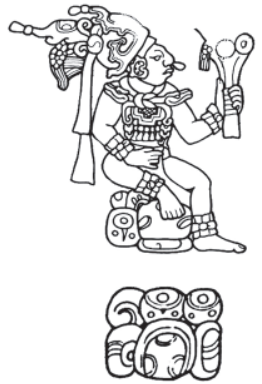

wa-la-cha-li
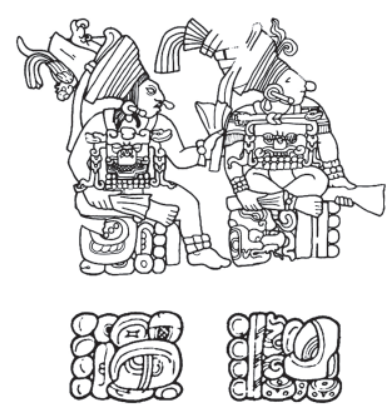

4-TE'-AJAW-wa 9-K'AWIL

Fig. 8 - Paralelos en la lista de dioses patronos en la banqueta esculpida del Templo 11 y en la Estela 13 de Copán, incluyendo a we-ku-?ma y wa-la-cha-li.

Basado en los dibujos de L. Schele (Schele y Schele 2000, n. ${ }^{\circ} 1049,1040$ ).

'agua'"1; al ser así, se trata de un dios de origen no maya procedente del oeste de Honduras o El Salvador, indicando la presencia y relevancia sociopolítica de grupos de esta área en Copán en los siglos VII y VIII.

\section{Distinción}

Al mismo tiempo que se notan estas tendencias de integrar a la población cada vez más amplia y más diversa en el ritual estatal y las expresiones culturales mayas, también se detectan claros indicadores de distinción étnica. Primero, se nota que la asimilación de nuevas deidades ocurre evidentemente en un esquema ritual maya, empezando con su actor principal, el gobernante, quien -basándonos en los textos que mandó a esculpir en piedra-celebraba la evocación de dioses y ofrendas de acuerdo con los cánones rituales peteneros. Para enfatizar el carácter maya de estos rituales, algunos textos citan antecedentes en el pasado remoto. Así debemos entender las referencias a "Ajaw Foliado" en Chihka', una narrativa que parece tener su origen en Tikal y que expresa un discurso claro de origen y pertenencia étnica del gobernante.

Segundo, también los monumentos mismos, los cuales en conjunto con sus ofrendas representan los indicadores más claros para el ritual público, son claramente marcados como mayas, empezando con el uso de la escritura que refleja la lengua maya clásica. Esta escritura fue un código de la élite alta. Poca gente sabía leer o escribir, lo cual no solo define las estelas jeroglíficas como

11. La documentación de las lenguas lenca es muy fragmentada (Campbell, Chapman y Dakin 1978, p. 330-331; Campbell 1976, p. 73-74). No obstante, la raíz wal ( war) 'agua' es atestiguada en lenca salvadoreño (o de Chilanga) (Río Urrutia 2004, p. 290, 297, 303, 306-308; Constenla Umaña 2002, p. 191-192). 
medios de la población maya, sino también de los especialistas intelectuales de la corte real y sobre todo del gobernante (Houston y Stuart 1992; Houston 1994), vinculando el estatus étnico (maya) con los más altos estatus sociopolíticos. De esta manera, la integración de una población amplia en el ritual estatal era al mismo tiempo una estrategia de distinción: muchos de los códigos usados -entre ellos no sólo la escritura, sino también el lenguaje ritual y la personificación de dioses- eran exclusivos de una élite maya que se consideraba petenera. Las estelas fuera del núcleo urbano muestran esto de manera muy clara. Ninguna de ellas portaba imágenes del gobernante; sus cuatro lados fueron esculpidos con textos largos, convirtiéndolas en manifestaciones públicas de un código exclusivo que marcaba la diferencia entre los sabios que gobernaban y todos los demás. Es interesante notar que entonces no se legitima tanto al k'uhul ajaw sino a "los mayas" como sustentantes del poder, tanto en ese momento como en el pasado ${ }^{12}$.

De esta manera reconocemos una segunda ola de "mayanización" en el valle de Copán en el siglo viI, dos siglos después de la llegada de Yax K'uk' Mo'. K'ahk' Uti' Juun Witz' K'awiil comisionó una serie de estelas de alta especificidad cultural, marcando el valle como territorio maya, en el sentido de una "cultura elevada inclusiva" (Assmann 2011, p. 126), es decir, una "alta cultura" o de élite. Algunos objetos rituales no y, probablemente, pre-mayas fueron removidos del espacio público, respetuosamente enterrándolos debajo de estelas mayas; un acto que claramente simbolizaba el nuevo dominio maya sobre otras ideologías y religiones. Dioses locales o foráneos fueron mayanizados integrándolos en el panteón estatal. La difusión e imposición de la ideología maya fue necesaria para asegurar que los mecanismos de legitimación del gobernante siguieran funcionando.

El desarrollo de un elitismo cultural como mecanismo de distinción aumentó en el siglo VIII. En lugar de seguir con los esfuerzos de reunir toda la población bajo un solo esquema sociocultural, se nota una paulatina descentralización del poder político, lo cual significa que el gobernante elevó el estatus de otras élites, las cuales a su vez administraban ciertos sectores poblacionales. Los primeros indicadores de este mecanismo se encuentran en centros secundarios remotos como Río Amarillo (Schele 1987) y probablemente Santa Rita en el siglo VII ${ }^{13}$, donde élites secundarias comisionaron monumentos esculpidos (bajo

12. El formato de las estelas completamente jeroglíficas, es decir, sin imágenes, es un arcaísmo en el sentido de que revive el formato canónico de las estelas del siglo $\mathrm{v}$ y de la primera mitad del siglo vi. En este sentido, las estelas del valle también establecen un vínculo formal con las tradiciones de la élite maya del Clásico temprano, creando la ilusión de continuidad cultural a través de varios siglos.

13. Es posible que la élite de Santa Rita haya migrado del Petén a este sitio en esta época. A pesar de que la Estela 23 fue fragmentada cuando la documentó Morley (1920, p. 147151), el autor describe el grabado frontal con un personaje de perfil y un texto jeroglífico 
los auspicios del gobernante) para consolidar sus propias esferas del ritual estatal (maya) (ver también von Schwerin 2010). No obstante, ya en el siglo VIII observamos el mismo patrón en el núcleo urbano, sobre todo en Las Sepulturas y El Bosque. En esta época, la escultura se vuelve mucho más privada. Para el reinado del decimosexto gobernante Yax Pahsaj Chan Yopaat a finales del siglo VIII, el formato de estela había caído en desuso y ya no se elaboraban esculturas para la Gran Plaza ${ }^{14}$. Por el contrario, los monumentos esculpidos de este gobernante se caracterizan por su ubicación en espacios mucho más restringidos, principalmente en la Acrópolis y en el palacio real. Las expresiones gráficas monumentales se habían convertido en algo más exclusivo para presumir ante un público muy específico. Las élites sub-reales, que cada vez participaban más en los asuntos estatales, obtuvieron el privilegio de acceder a estos espacios monumentales y detalladamente decorados y de reproducirlos en sus propias residencias (ver Fash W. 2005, p. 94-101). La recepción del arte ya no era para todos sino solo para un grupo selecto de altos mandatarios. Esta forma de elitismo se observa desde antes en sitios como Palenque, donde la escultura en estuco o piedra siempre estaba lejos del público general, adentro de templos y palacios o en las fachadas de edificios encima de plataformas elevadas, a una altura considerable sobre las cabezas de la gente en las plazas.

\section{Discusión}

A lo largo de este texto se han presentado datos e interpretaciones que sugieren que: 1) los gobernantes clásicos de Copán compartían una identidad cultural basada en su origen petenero o incluso tikaleño; 2) ante la diversidad cultural en y alrededor de Copán, esta herencia cultural fue elevada al nivel de una "alta cultura" en el sentido de una estructura semiótica dominada por la élite dominante; 3) la integración en la dinámica general, y sobre todo ritual, de la alta cultura -la cual también podríamos considerar como proceso de mayanización- sucedió en dos fases principales, la primera correspondiendo a la fundación dinástica en el siglo v y la segunda al siglo vII; 4) en el siglo VII, la mayanización se extendió más allá del núcleo urbano hacia el hinterland como reacción al incremento poblacional y la diversificación cultural en esta época; 5) mientras que los mensajes políticos del discurso monumental en el núcleo urbano enfatizan la persona del gobernante, las estelas del hinterland ponen énfasis en los códigos de una élite gobernante maya más amplia, lo cual refleja la importancia del factor cultural en el ámbito rural; 6) en el siglo vIII,

en forma de "L". Este formato no existe en las estelas de Copán del siglo VII, sino retoma claramente formas canónicas de las tierras bajas centrales del Clásico tardío.

14. La única estela de este periodo es la Estela 8 (783 d.C.) que fue erigida fuera del Grupo 10 (Morley 1920, p. 340-341). 
se intensificó la segmentación del Estado, lo cual implicó que cada vez menos monumentos fueron creados para espacios públicos, mientras que incrementó la producción de esculturas para los espacios privados y semi-privados controlados por distintas élites; 7) a finales del periodo Clásico, las tensiones multi-étnicas parecen haberse manejado en entidades sociopolíticas más pequeñas, pero ya no a nivel estatal, lo cual se debe probablemente al tamaño de la población, tanto en el núcleo urbano, como en la periferia rural. Tomando en cuenta este desarrollo, sugiero entonces que uno de los factores que contribuyeron al "colapso" del Estado copaneco debe consistir en la desvalorización de la alta cultura maya y de la ideología que esta sustentaba. Mientras que la imposición de una cultura normalizada era posible en una ciudad ritualmente y políticamente centralizada, la descentralización bajo la presión del incremento demográfico dio lugar al desafío de la supuesta superioridad de lo maya y al auge de expresiones culturales y étnicas subalternas.

El dialogo estratégico entre la integración centralista y la distinción vertical se presenta en estructuras estatales "transétnicas" de diferentes épocas en diferentes partes del mundo, como Egipto o Mesopotamia (Assmann 2011, p. 125-141, 156). La religión, por un lado, es un elemento integrador (ver Durkheim 1982), politizado a través de la concentración de sus expresiones dominantes en la persona del gobernante. Por el otro lado, los códigos que la implementan - especialmente la escritura- son de alta especialización y marcan distinciones sociales en el sentido de una participación disimilar en las prácticas y los conocimientos culturales. Esto causa la formación de una élite que no sólo se distingue por su estatus económico, sino también por sus competencias culturales avanzadas. La participación hegemónica de la élite en las prácticas, en la memoria y en las creencias de la cultura integradora legitimaba su estatus y el orden social a nivel ideológico. Esto significa que la élite se reproducía como tal a través de las prácticas simbólicas transmitidas entre sus miembros. En el caso de Copán, es posible que la descentralización o apertura de esta élite cultural haya distorsionado la transmisión intergeneracional de los conocimientos especializados y con ello la reproducción tanto de las prácticas de la alta cultura como de la élite misma como grupo social.

De esta manera, el auge y la caída de Copán como ciudad y como Estado parecen haber dependido de la centralización de una alta cultura (o, en términos de Assmann [2011], "memoria cultural") derivada de los cánones peteneros del siglo v. La estructura participativa de esta alta cultura se plasmó de manera más detallada en el núcleo urbano, donde el gobernante enfatizaba constantemente su posición y competencia privilegiada. No obstante, en la periferia y en el hinterland, la resolución discursiva es más baja; ahí se enfatizaban, de manera más general, los conocimientos culturales más elevados, convirtiendo el discurso político-jerárquico en un discurso político-étnico. Esto sugiere, desde 
un punto de vista epigráfico, que la población del núcleo urbano de Copán del siglo VII ya era una población "mayanizada", mientras que la población periférica debe de haber sido étnicamente mucho más heterogénea obedeciendo a dinámicas complejas de distinción, emulación y asimilación (ver Schortman y Nakamura 1991; Schortman y Urban 1994; Canuto y Bell 2017). A pesar del incremento poblacional en el siglo VIII (Webster 2005), la hegemonía cultural maya parece haber estado bien establecida en este periodo, ya que el discurso monumental enfatiza más y más la distinción vertical. Esta última parece haber estado presente en muchos sitios mayas clásicos, tanto en el centro como en la periferia del área maya, mientras que la integración cultural es particularmente visible en Copán. Esto proporciona un precedente interesante para futuras investigaciones comparativas sobre los sitios mayas periféricos y las dinámicas culturales que se desarrollaron en ellos. *

* Manuscrit reçu en février 2018, accepté pour publication en novembre 2018.

Agradecimientos - Agradezco a la Universidad Nacional Autónoma de México (UNAM), la Coordinación de Humanidades y el Instituto de Investigaciones Antropológicas por su apoyo durante mi estancia posdoctoral. También gracias al Instituto Hondureño de Antropología e Historia (IHAH) y el Centro Regional de Investigaciones Arqueológicas (CRIA) en Copán por su apoyo con permisos y asistencia bibliográfica. Además, expreso mi agradecimiento sincero a Chloé Andrieu por su apoyo con traducciones, a Verónica Amellali Vázquez López por sus comentarios y correcciones, así como a Shintaro Suzuki por la retroalimentación continua.

\section{Referencias citadas}

Agurcia Fasquelle Ricardo y Barbara W. Fash

2005 "The evolution of structure 10L-16, heart of the Copán Acropolis", in E. Wyllys Andrews y William L. Fash (eds), Copán. The history of an Ancient Maya kingdom, School of American Research Press, Santa Fe, p. 201-237.

Andrews E. Wyllys y Cassandra R. Bill

2005 “A Late Classic royal residence at Copán”, in E. Wyllys Andrews y William L. Fash (eds), Copán. The history of an Ancient Maya kingdom, School of American Research Press, Santa Fe, p. 239-314.

Arnauld M. Charlotte

2012 "Neighborhoods and intermediate units of spatial and social analysis in Ancient Mesoamerica", in M. Charlotte Arnauld, Linda R. Manzanilla y Michael E. Smith (eds), The neighborhood as a social and spatial unit in Mesoamerican AsHMORE Wendy cities, University of Arizona Press, Tucson, p. 304-320.

1984 "Quirigua archaeology and history revisited", Journal of Field Archaeology, 11 (4), p. 365-386. 
Assmann Jan

2011 Cultural memory and early civilization. Writing, remembrance, and political imagination, Cambridge University Press, Cambridge/New York.

BARON Joanne P.

2013 Patrons of La Corona. Deities and power in a Classic Maya Community, tesis de doctorado, antropología, University of Pennsylvania, Filadelfia.

2016 Patron gods and patron lords. The semiotics of classic Maya community cults, University of Colorado Press, Boulder.

BECKER Marshall Joseph

2009 "Tikal: evidence for ethnic diversity in a Prehispanic Lowland Maya state capital", in Linda R. Manzanilla y Claude Chapdelaine (eds), Domestic life in prehispanic capitals. A study of specialization, hierarchy, and ethnicity, Bíró Péter University of Michigan, Museum of Anthropology, Ann Arbor, p. 89-104.

2017 “A new Teotiwa Lord of the South: K'ahk' Uti' Chan Yopat (578-628 C.E.) and the renaissance of Copan", Glyph Dwellers, 57.

Bíró Péter y Albert DavLETSHIN

2011 Foreign words in the inscriptions of Copan, manuscrito inédito.

Buikstra Jane E., T. Douglas Price, Lori E. Wright y James A. Burton

2004 "Tombs from the Copan acropolis: a life-history approach", in Ellen E. Bell, Marcello A. Canuto y Robert J. Sharer (eds), Understanding Early Classic Copan, University of Pennsylvania, Museum of Archaeology and Anthropology, Philadelphia, p. 191-212.

CAmpBell Lyle

1976 “The Last Lenca”, International Journal of American Linguistics, 42 (1), p. 73-78.

CAmpbell Lyle, Anne Chapman y Karen Dakin

1978 "Honduran Lenca", International Journal of American Linguistics, 44 (4), p. 330-332.

CAnuto Marcello A.

2002 A tale of two communities. Social and political transformation in the Hinterlands of the Maya Polity of Copan, tesis de doctorado, antropología, University of Pennsylvania, Filadelfia.

2004 "The rural settlement of Copan: changes through the Early Classic", in Ellen E. Bell, Marcello A. Canuto y Robert J. Sharer (eds), Understanding Early Classic Copan, University of Pennsylvania, Museum of Archaeology and Anthropology, Philadelphia, p. 29-50.

Canuto Marcello A. y Ellen E. Bell

2013 "Archaeological investigations in the El Paraíso Valley: the role of secondary centers in the multiethnic Landscape of Classic Period Copan", Ancient Mesoamerica, 24 (1), p. 1-24.

2017 "Considering the edge effect: ethnogenesis and Classic Period society in the Southeastern Maya area", in Bethany J. Beyyette y Lisa J. LeCount (eds), The only true people. Linking Maya identities past and present, University Press of Colorado, Boulder, p. 219-241. 
Integración y distinción cultural en el paisaje urbano y rural de Copán

CANuto Marcello A. y William L. FAsH

2004 "The blind spot: where elite and non-elite meet", in Charles W. Golden y Greg Borgstede (eds), Continuities and changes in Maya Archaeology, Routledge, New York/London, p. 47-70.

CARTER Nicholas P.

2014 "Space, time, and texts: a landscape approach to the Classic Maya hieroglyphic record", in Matthew T. Rutz y Morag M. Kersel (eds), Archaeologies of text. Archaeology, technology, and Ethics, Oxbow Books, Oxford/Philadelphia, p. 31-58.

Chase Diane Z., Arlen F. Chase y William A. Haviland

1990 "The Classic Maya city: reconsidering the "Mesoamerican urban tradition", American Anthropologist, 92 (2), p. 499-506.

CheEk Charles D.

1983 "Las excavaciones en la Plaza principal: resumen y conclusiones", in Proyecto Arqueológico Copán, Introducción a la arqueología de Copán, Honduras 2, Secretaría de Estado en el Despacho de Cultura y Turismo, Tegucigalpa, p. 319-348.

Constenla Umaña Adolfo

2002 "Acerca de la relación genealógica de las lenguas lencas y las lenguas misumalpas", Filología y Lingüística, 28 (1), p. 189-205.

DuRKHEIM Émile

1982 Las formas elementales de la vida religiosa, Akal Editor, Madrid.

FAHSEn Federico, Linda Schele y Nikolai GrubE

1995 "The Tikal-Copan connection: shared features. Version 2", Copan Notes, 123.

FAsH Barbara W.

1992 "Late Classic architectural sculpture themes in Copan", Ancient Mesoamerica, 3 (1), p. 89-104.

2004 "Early Classic sculptural development at Copan", in Ellen E. Bell, Marcello A. Canuto y Robert J. Sharer (eds), Understanding Early Classic Copan, University of Pennsylvania, Museum of Archaeology and Anthropology, Philadelphia, p. 251-264.

FASH William L.

1983 "Reconocimiento y excavaciones en el valle", in Proyecto Arqueológico Copán, Introducción a la arqueología de Copán, Honduras 1, Secretaría de Estado en el Despacho de Cultura y Turismo, Tegucigalpa, p. 229-469.

2001 Scribes, warriors, and kings. The city of Copán and the Ancient Maya, Thames \& Hudson, London.

2005 "Toward a social history of the Copán Valley", in E. Wyllys Andrews y William L. Fash (eds), Copán. The history of an Ancient Maya kingdom, School of American Research Press, Santa Fe, p. 73-101.

FASH William L. y Barbara W. FASH

2006 "Ritos de fundación en una ciudad pluri-étnica: cuevas y lugares sagrados lejanos en la reivindicación del pasado en Copán", in María Josefa Iglesias Ponce de León, Rogelio Valencia Rivera y Andrés Ciudad Ruiz (eds), Nuevas ciudades, nuevas patrias. Fundación y relocalización de ciudades en Mesoamérica 
y el Mediterráneo antiguo, Sociedad Española de Estudios Mayas, Madrid, p. 105-129.

FASH William L. y Kurt Z. LONG

1983 "Mapa arqueológico del valle de Copán”, in Proyecto Arqueológico Copán, Introducción a la arqueología de Copán, Honduras 3 Mapas, Secretaría de Estado en el Despacho de Cultura y Turismo, Tegucigalpa.

GARcía BARrios Ana

2008 Chaahk, el dios de la lluvia, en el periodo Clásico maya: aspectos religiosos y políticos, tesis de doctorado, Antropología de América, Universidad Complutense de Madrid, Madrid.

Gerstle Andrea Irene

1988 Maya-Lenca ethnic relations in Late Classic Period Copan, Honduras, tesis de doctorado, antropología, University of California, Santa Barbara, Ann Arbor.

Grube Nikolai

1990 "A reference to Water-Lily Jaguar on Caracol Stela 16", Copan Notes, 68.

Grube Nikolai, Linda Schele y Federico FAHSEN

1995 "The Tikal-Copan connection: evidence from external relations. Version 2", Copan Notes, 121.

Hellmuth Nicholas M.

1987 Monster und Menschen in der Maya-Kunst, Akademische Druck- u. Verlagsanstalt, Graz.

Helmke Christophe

2012 "Mythological emblem glyphs of Ancient Maya kings", Contributions in New World Archaeology, 3, p. 91-126.

Helmke Christophe, Jaime J. Awe, Shawn G. Morton y Gyles Iannone

2015 "The text and context of the Cuychen Vase, Macal Valley, Belize", in Charles Golden, Stephen Houston y Joel Skidmore (eds), Maya Archaeology 3, Precolumbia Mesoweb Press, San Francisco, p. 8-29.

Houston Stephen D.

1994 "Literacy among the Pre-Columbian Maya: a comparative perspective", in Elisabeth H. Boone y Walter D. Mignolo (eds), Writing without words. Alternative literacies in Mesoamerica and the Andes, Duke University Press, Durham, p. 27-49.

Houston Stephen D. y David StuarT

1992 “On Maya hieroglyphic literacy”, Current Anthropology, 33 (5), p. 589-593. Hull Kerry M.

2012 "Poetic tenacity: a diachronic study of Kennings in Mayan languages", in Kerry M. Hull y Michael D. Carrasco (eds), Parallel worlds. Genre, discourse, and poetics in contemporary, colonial, and Classic Period Maya literature, University Press of Colorado, Boulder, p. 73-122.

IsENDAHL Christian y Michael E. SMith

2013 "Sustainable agrarian urbanism: the low-density cities of the Mayas and Aztecs", Cities, 31, p. 132-143.

Jones Christopher y Linton SATterthwaite

1982 The monuments and inscriptions of Tikal, Tikal Report 33-A, University Museum, University of Pennsylvania, Philadelphia. 
Integración y distinción cultural en el paisaje urbano y rural de Copán

Kupprat Felix

2015 La memoria cultural y la identidad maya en el periodo Clásico. Una propuesta de método y su aplicación a los casos de Copán y Palenque en el siglo VII d.C., tesis de doctorado, Estudios Mesoamericanos, Universidad Nacional Autónoma de México, México.

Lacadena García-Gallo Alfonso y Søren Wichmann

2002 "The distribution of Lowland Maya languages in the Classic Period", in Vera Tiesler Blos, Rafael Cobos y Merle Greene Robertson (eds), La organización social entre los mayas prehispánicos, coloniales y modernos. Memoria de la Tercera Mesa Redonda de Palenque, Instituto Nacional de Antropología e Historia, Universidad Autónoma de Yucatán, México, Mérida, tomo 2, p. 275-319.

LONGYEAR John M.

1952 Copan ceramics. A study of southeastern Maya pottery, Carnegie Institution of Washington, Washington (DC).

LOOper Matthew G.

1999 "New perspectives on the Late Classic political history of Quirigua, Guatemala", Ancient Mesoamerica, 10 (2), p. 263-280.

MACA Allan L.

2015 "Tomb 68-1, Copan: deducing polity dynamics during the Early Classic Period and Beyond", in Damien B. Marken y James L. Fitzsimmons (eds), Classic Maya polities of the southern lowlands, University Press of Colorado, Boulder, p. 167-193.

MANZANILla Linda R.

2015 "Cooperation and tensions in multiethnic corporate societies using Teotihuacan, Central Mexico, as a case study", Proceedings of the National Academy of Sciences, 112 (30), p. 9210-9215.

MARTIN Simon

2000 “Los señores de Calakmul”, Arqueología Mexicana, 42, p. 40-45.

2004 "Preguntas epigráficas acerca de los escalones de Dzibanché", in Enrique Nalda (ed.), Los cautivos de Dzibanché, Instituto Nacional de Antropología e Historia, México, p. 105-115.

MARTIN Simon y Nikolai GruBE

2008 Chronicle of the Maya kings and queens. Deciphering the dynasties of the Ancient Maya, Thames \& Hudson, London.

Maudslay Alfred P.

1902 Biologia Centrali-Americana, or, Contributions to the knowledge of the fauna and flora of Mexico and Central America. Archaeology, R.H. Porter, Dulau \& Co., London.

Miller Katherine A.

2015 "Family, 'foreigners', and fictive kinship: a bioarchaeological approach to social organization at Late Classic Copan", tesis de doctorado, Arizona State University, Phoenix.

Morley Sylvanus Griswold

1920 The inscriptions at Copan, Carnegie Institution (Publication, 219), Washington (DC). 
Prager Christian M.

2013 Übernatürliche Akteure in der Klassischen Maya-Religion. Eine Untersuchung zu intrakultureller Variation und Stabilität am Beispiel des k'uh "Götter"Konzepts in den religiösen Vorstellungen und Überzeugungen Klassischer Maya-Eliten (250-900 n. Chr.), tesis de doctorado, Antropología de las Américas, Universität Bonn, Bonn.

Prager Christian M., Beniamino Volta y Geoffrey E. Braswell

2014 "The dynastic history and archaeology of Pusilha, Belize", in Geoffrey E. Braswell (ed.), The Maya and their Central American neighbors. Settlement patterns, architecture, hieroglyphic texts, and ceramics, Routledge, London/ New York, p. 245-307.

Prager Christian y Elisabeth Wagner

2017 "Historical implications of the Early Classic hieroglyphic text CPN 3033 on the sculptured step of Structure 10L-11-Sub-12 at Copan", Textdatenbank und Wörterbuch des Klassischen Maya. Research Note, 7.

Price T. Douglas, James H. Burton, Paul D. Fullagar, Lori E. Wright, Jane E. Buikstra y Vera Tiesler

2008 "Strontium isotopes and the study of human mobility in Ancient Mesoamerica", Latin American Antiquity, 19 (2), p. 167-180.

Price T. Douglas, James H. Burton, Robert J. Sharer, Jane E. Buikstra, Lori E. Wright, Loa P. Traxler y Katherine A. Miller

2010 "Kings and commoners at Copan: isotopic evidence for origins and movement in the Classic Maya Period", Journal of Anthropological Archaeology, 29, p. 15-32.

Price T. Douglas, Linda R. Manzanilla y William D. Middleton

2000 "Immigration and the ancient city of Teotihuacan in Mexico: a study using strontium isotope ratios in human bone and teeth", Journal of Archaeological Science, 27 (10), p. 903-913.

Price T. Douglas, Seiichi Nakamura, Shintaro Suzuki, James H. Burton y Vera Tiesler

2014 "New isotope data on Maya mobility and enclaves at Classic Copan, Honduras", Journal of Anthropological Archaeology, 36, p. 32-47.

RATTRAY Evelyn Childs

1987 “Los barrios foráneos de Teotihuacan”, in Emily McClung de Tapia y Evelyn Childs Rattray (eds), Teotihuacan. Nuevos datos, nuevas síntesis, nuevos problemas, Instituto de Investigaciones Antropológicas, Universidad Nacional Autónoma de México, México, p. 243-273.

RiEsE Berthold y Claude F. BAUdez

1983 "Esculturas de las estructuras 10L-2 y 4", in Proyecto Arqueológico Copán, Introducción a la arqueología de Copán, Honduras 2, Secretaría de Estado en el Despacho de Cultura y Turismo, Tegucigalpa, p. 143-190.

Río URrutia Ximena del

2004 "El lenca de Chilanga: léxico", Filología y Lingüística, 30 (1), p. 289-313.

SÁnchez Gamboa Ángel Adrián

2012 “Culto a los dioses remeros en Copán”, Kin Kaban, 2, p. 13-27. 
Integración y distinción cultural en el paisaje urbano y rural de Copán

SANDERS William T. y David Webster

1988 “The Mesoamerican urban tradition”, American Anthropologist, 90 (3), p. 521-546.

SCHELE Linda

1987 "Notes on the Rio Amarillo Altars", Copan Notes, 37.

1990a "The Early Classic dynastic history of Copán: Interim Report 1989”, Copan Notes, 70.

1990b “A new fragment from Altar J", Copan Notes, 74.

SCHELE Linda y Nikolai GRUBE

1987 "The brother of Yax-Pac", Copan Notes, 20.

1988 "Stela 13 and the East Quadrant of Copán”, Copan Notes, 44.

SCHEle Linda, Nikolai Grube y Federico FAHSEN

1995 "The Tikal-Copan connection: the Copan evidence. Version 2", Copan Notes, 122.

Schele Linda y David Schele

2000 "The Linda Schele drawings collection", Foundation for the Advancement of Mesoamerican Studies, Inc., http://research.famsi.org/schele.html, consultado el 08/08/2015.

Schortman Edward M. y Patricia A. URban

1994 "Living on the edge: core/periphery relations in Ancient Southeastern Mesoamerica", Current Anthropology, 35 (4), p. 401-430.

SCHORTMAN Edward M. y Seiichi NAKAMURA

1991 "A crisis of identity: Late Classic competition and interaction on the southeast Maya periphery", Latin American Antiquity, 2 (4), p. 311-336.

SCHWERIN Jennifer von

2010 "The problem of the 'Copan Style' and poltical identity: the architectural sculpture of El Paraíso, Honduras in a regional context", Mexicon, 32 (3), p. 56-66.

SHARER Robert J.

1978 "Archaeology and history at Quirigua, Guatemala", Journal of Field Archaeology, 5 (1), p. 51-70.

1988 “Quirigua as a Classic Maya Center”, in Elisabeth H. Boone y Gordon R. Willey (eds), The Southeast Classic Maya zone. A Symposium at Dumbarton Oaks, 6th and 7th October, 1984, Dumbarton Oaks Research Library and Collection, Washington (DC), p. 31-65.

1990 Quirigua. A Classic Maya center and its sculptures, Carolina Academic Press, Durham.

2004 "External Interaction at Early Classic Copan”, in Ellen E. Bell, Marcello A. Canuto y Robert J. Sharer (eds), Understanding Early Classic Copan, University of Pennsylvania, Museum of Archaeology and Anthropology, Philadelphia, p. 299-317.

Sharer Robert J., David W. Sedat, Loa P. Traxler, Julia C. Miller y Ellen E. Bell

2005 "Early Classic royal power in Copan: the origins and development of the Acropolis (ca. AD 250-600)", in E. Wyllys Andrews y William L. Fash (eds), Copán. The history of an Ancient Maya kingdom, School of American Research Press, Santa Fe, p. 139-199. 
Sharer Robert J. y Loa P. Traxler

2006 "The Foundations of ethnic diversity in the Southeastern Maya area", in Frauke Sachse (ed.), Maya ethnicity. The construction of ethnic identity from Preclassic to Modern times, Verlag Anton Saurwein, Markt Schwaben, p. 31-43.

SMith Michael E.

2010 "The archaeological study of neighborhoods and districts in ancient cities", Journal of Anthropological Archaeology, 29, p. 137-154.

2011 "Classic Maya settlement clusters as urban neighborhoods: a comparative perspective on low-density urbanism”, Journal de la Société des américanistes, 97 (1), p. 51-73.

Smith Michael E. y Juliana Novic

2012 "Introduction: neighborhoods and districts in Ancient Mesoamerica", in M. Charlotte Arnauld, Linda R. Manzanilla y Michael E. Smith (eds), The neighborhood as a social and spatial unit in Mesoamerican cities, University of Arizona Press, Tucson, p. 1-26.

Sмiтн Robert E.

1955 Ceramic sequence at Uaxactun, Guatemala, Middle American Research Institute, Tulane University, Nueva Orleans.

Somerville Andrew D., Margaret J. Schoeninger y Geoffrey E. Braswell

2016 "Political alliance, residential mobility, and diet at the Ancient Maya City of Pusilha, Belize", Journal of Anthropological Archaeology, 41, p. 147-158.

STRÖMSVIK Gustav

1941 Substela caches and stela foundations at Copán and Quiriguá, Carnegie Institution of Washington, Washington (DC).

Stuart David

1992 "Hieroglyphs and archaeology at Copan”, Ancient Mesoamerica, 3 (1), p. 169-184.

2000 “"The arrival of strangers': Teotihuacan and Tollan in Classic Maya history”, in David Carrasco, Lindsay Jones y Scott Sessions (eds), Mesoamerica's Classic heritage. From Teotihuacan to the Aztecs, University Press of Colorado, Boulder, p. 465-513.

2004 "The Beginnings of the Copan dynasty", in Ellen E. Bell, Marcello A. Canuto y Robert J. Sharer (eds), Understanding Early Classic Copan, University of Pennsylvania, Museum of Archaeology and Anthropology, Philadelphia, p. 215-247.

2007 "The origin of Copan's founder", Maya Decipherment, https://decipherment.wordpress.com/2007/06/25/the-origin-of-copans-founder/, consultado el 17/06/2019.

2017 "The gods of heaven and earth: evidence of Ancient Maya categories of deities", in Eduardo Matos Moctezuma y Ángela Ochoa Peralta (eds), Del Saber ha hecho su razón de ser... Homenaje a Alfredo López Austin, Instituto Nacional de Antropología e Historia, Instituto de Investigaciones Antropológicas, Universidad Nacional Autónoma de México, México, tomo 1, p. 247-267. 
Integración y distinción cultural en el paisaje urbano y rural de Copán

Stuart David y Stephen D. Houston

1994 Classic Maya place names. Studies in Pre-Columbian art and archaeology, Dumbarton Oaks Research Library and Collection, Washington (DC).

Stuart David y Nikolai Grube

2000 A new inscription from Nim Li Punit, Belize, Research Reports on Ancient Maya Writing, 45, Center for Maya Research, Washington (DC).

SuZuKI Shintaro

2015 Población y organización socio-politica en el valle de Copán, Honduras, durante el periodo Clásico, y sus implicaciones en la dinámica de fundación y colapso del Estado copaneco, tesis de doctorado, Estudios Mesoamericanos, Universidad Nacional Autónoma de México, México.

TAUBE Karl

2004 "Structure 10L-16 and its Early Classic antecedents: fire and the evocation and resurrection of K'inich Yax K'uk' Mo"', in Ellen E. Bell, Marcello A. Canuto y Robert J. Sharer (eds), Understanding Early Classic Copan, University of Pennsylvania, Museum of Archaeology and Anthropology, Philadelphia, p. 265-295.

TIESLER Vera

2014 The bioarchaeology of artificial cranial modifications. New approaches to head shaping and its meanings in Pre-Columbian Mesoamerica and beyond. Interdisciplinary contributions to archaeology, Springer, New York.

ToKovinine Alexandre

2008 The power of place. Political Landscape and identity in Classic Maya inscriptions, imagery y architecture, tesis de doctorado, Antropología, Harvard University, Cambridge, Massachusetts.

Tsukamoto Kenichiro, Javier López CAmacho, Luz Evelia Campaña ValenZuela, Hirokazu Kotegawa y Octavio Q. Esparza Olguín

2015 "Political interactions among social actors: spatial organization at the Classic Maya polity of El Palmar, Campeche, Mexico", Latin American Antiquity, 26 (2), p. 200-220.

VelÁSQUez García Erik

2010 "Los dioses remeros mayas y sus posibles contrapartes nahuas", in Laura van Broekhoven, Rogelio Valencia Rivera, Benjamin Vis y Frauke Sachse (eds), The Maya and their neighbours. Internal and external contacts through time, Verlag Anton Saurwein, Markt Schwaben, p. 115-131.

VIEL René

1999 "El periodo Formativo de Copan, Honduras", in Juan Pedro Laporte y Héctor Escobedo (eds), XII Simposio de investigaciones arqueológicas en Guatemala, 1998, Museo Nacional de Arqueología y Etnología, Guatemala, p. 96-101.

VIEL René y Jay HaLl

2000 "Las relaciones entre Copan y Kaminaljuyu", in Juan Pedro Laporte, Héctor Escobedo, Bárbara Arroyo y Ana Claudia Monzón de Suasnávar (eds), XIII Simposio de investigaciones arqueológicas en Guatemala, 1999, Museo Nacional de Arqueología y Etnología, Guatemala, p. 107-111. 
WeBster David

2005 "Political ecology, political economy, and the culture history of resource management at Copán", in E. Wyllys Andrews y William L. Fash (eds), Copán. The history of an Ancient Maya kingdom, School of American Research Press, Santa Fe, p. 33-72.

Webster David L., AnnCorinne Freter y Nancy Gonlin

2000 Copán. The rise and fall of an Ancient Maya kingdom. Case studies in cultural anthropology, Wadsworth, Belmont.

Webster David y William T. SANDERS

2001 "La antigua ciudad Mesoamericana: teoría y concepto", in Andrés Ciudad Ruiz, María Josefa Iglesias Ponce de León y María del Carmen Martínez de Martínez (eds), Reconstruyendo la ciudad Maya. El urbanismo en las sociedades antiguas, Sociedad Española de Estudios Mayas, Madrid, p. 43-64.

Willey Gordon R., Richard M. Leventhal, Arthur A. Demarest y William L. Fash

1994 Ceramics and artifacts from excavations in the Copan residential zone, Peabody Museum of Archaeology and Ethnology, Harvard University, Cambridge. 